\title{
ENVIRONMENTAL APPLICATIONS OF AIRBORNE GEOPHYSICS IN FINLAND
}

\author{
Jouni Lerssi *, Maija Kurimo, Tarmo Jokinen, Erkki Lanne ** and Risto Puranen \\ Geological Survey of Finland \\ FIN-02150 Espoo, ${ }^{*}$ FIN-70211 Kuopio, **FIN-96101 Rovaniemi \\ Finland
}

\section{INTRODUCTION}

Geological Survey of Finland (GSF) has carried out systematic airborne geophysical surveys in Finland since 1951. The second program started in 1972 using a flight altitude of 30-40 meters and line spacing of $200(100)$ meters (Kurimo, et al, 1986; Peltoniemi, 1982; Poikonen, 1991; Vironmäki, et al, 1982). Today $80 \%$ of the country has been measured. The measurements have been made with fixed-wing aircraft. The differential GPS is utilised in mavigation. In low-altitude measurements the following systems are in use: magnetic, gamma radiation and vertical coplanar EM and VLF electromagnetic. Total magnetic field is measured with a wingtip gradiometer. The horizontal spacing between the sensors is 21 meters. Earth's gamma radiation is measured with a spectrometer which utilises a $251 \mathrm{NAI}$ crystal detector. In the electromagnetic unit a vertical coplanar coil configuration is used. The frequency is $3112 \mathrm{~Hz}$ (from 1995 also $14368 \mathrm{~Hz}$ ) and coil separation is $21.4 \mathrm{~m}$. GSF processes data with in-house software and profile, contour, shaded colour and grey scale maps are drawn (Kurimo, et al. 1986). The survey results are used in mineral exploration and geological mapping, recently also increasingly in environmental applications.

GSF has conducted aerogeophysical studies of some contaminated areas in Finland. In this paper we present three examples. Mäntyvaara landfill northwest of Rovaniemi in northern Finland is a potential risk dump (Hannula and Lanne, 1995). Lievestuore pulp mill led its waste effluent during 1935-1967 to the nearby Koivusensuo mire, where the 'famous' Lipeälampi waste pond was formed. Ämmässuo is a large modern municipal landfill of Helsinki region where the arrangements are up to date.

\section{MÄNTYVAARA LANDFILL AT ROVANIEMI, NORTHERN FINLAND}

The Mäntyvaara landfill was established in 1965 for municipal waste. The annual dumping volume is about 22000 tons (1990) and the dump is intended to be used up to 2001. The landfill lies on Carex-type peat mire. The thickness of the peat varies in the range $0.5-4 \mathrm{~m}$. Under the peat there is sandy and silty till. The thickness of the overburden is of the order of ten meters. The bedrock is assumed to be quartzite. The nearest municipal ground water supply is one kilometer away from the dump. The arrangement of the dump does not satisfy the prevailing standards and therefore it has been classified as a potential risk site.

In 1992 the region of Rovaniemi was mapped by airborne low-altitude geophysical methods. The Mäntyvaara landfill is clearly visible on the total field magnetic and aeroelectromagnetic (AEM) in-phase maps. The magnetic peak anomaly associated with the landfill is about $800 \mathrm{nT}$ and the peak value of the in-phase component is about $5300 \mathrm{ppm}$. Both magnetic and in-phase anomalies are probably caused by metallic waste.

On the quadrature component map (Fig. 1) the landfill causes a strong anomaly, the magnitude is $8200 \mathrm{ppm}$. East of this lies a weaker anomaly (peak value of $860 \mathrm{ppm}$ ). It can be related to waste water leakage. The length of this anomaly outside the landfill is more than 700 meters. Because of wide line spacing the accurate shape of the plume anomaly is uncertain and depends on the interpolation method used. According to layer model interpretations the conductance (conductivity * thickness) of the plume conductor is $0.1 \mathrm{~S}$. This layer is thin and lies just at the surface.

To get more detailed information and to explain the AEM-anomaly sources, conductivity measurements (EM31), VLF, resistivity sounding (DC), ground penetrating radar and seismic refraction surveys were carried out. 
All the geophysical ground methods reflecting electrical conductivity revealed and confirmed the airborne anomaly.

Surface and ground water samples were collected from ditches and wells. Peat samples were taken both inside and outside the conductive zone. Electrical conductivity and inorganic and organic compounds were analysed. Increased values of pollution indicators in water samples like $\mathrm{pH}$, conductivity, chlorine, sodium and potassium reveal the leakage from the landfill. The correlation of elevated sodium, potassium, barium and zinc concentrations with the conductive zone is excellent.

By combining geophysical results with chemical analyses, the contaminant plume could be verified. The salts dissolved from the waste dump are the reason for the electrical anomaly.

\section{LIPEÄLAMPI WASTE POND AT LIEVESTUORE, MIDDLE FINLAND}

Pulp mill waste effluent disposed of in Lipeälampi pond at Lievestuore during 1935-1967 is acid ( $\mathrm{pH}=2-3$ ) and contains much sodium lignosulfonate(NaLS), which is not usually present in natural waters (Mäkelä 1986). Because it contains hydrogen ions and dissolved solids, the effluent's electric conductivity is high and correlates with the high NaL.S concentrations. Spreading of the effluent into the soils surrounding the pond has enhanced the soil conductivity, which may be observed by AEM surveys or by electric logging in the field.

AEM surveys were carried out using the same measurement system as described earlier but using tighter (100 meter) line spacing. The AEM map compiled from the survey results (Fig. 2) shows a strongly anomalous area (dark grey), which is a clearly better conducting than the unpolluted glacial till and mire environment (light grey). The polluted area extends for over $200 \mathrm{~m}$, from the pond's northern side, to Koivusensuo mire, and for over $100 \mathrm{~m}$ to a depression zone on the pond's southeastern side. Along this zone the anomaly becomes weaker and continues to the lower-lying Lake Koivujärvi, reflecting the probable route of pollutant migration. The anomaly is caused by a zone in overburden, which is rich in water and fines and thus better conducting than the surrounding glacial tills.

A new type of conductivity probe was used in field measurements (Puranen et al. 1997). Logging was done at 30 sites, at $25 \mathrm{~cm}$ intervals from the surface down to the hard bottom sediment. The electric conductivity is highest (heaviest pollution) at the bottom of the central depression of Koivusensuo mire decreasing towards the surface and to the north, reaching background values beyond the oldest bordering ditch.

With the help of logged conductivities and layer thicknesses, layer models were made for the southern part of the pond, the mire depression and the central part of Lake Koivujärvi. From calculation of electromagnetic anomalies associated with the models and by comparison of these with measured anomalies on the AEM map, it can be concluded that there is more of polluted material underneath the pond than under the mire depression. Assuming that the polluted bottom sediment has a conductivity of $20 \mathrm{mS} / \mathrm{m}$, a layer model gives a polluted layer thickness of about $8 \mathrm{~m}$ under the pond, and of about $4 \mathrm{~m}$ under the mire depression. This modelling result agrees with drilling observations. From model interpretation, it can also be concluded that the anomaly at the central part of Koivujärvi (Fig. 2) is caused by a depression filled with lake sediments. Homewer, possible NaLS concentrations in the sediments cannot be estimated.

\section{ÄMMÄSSUO LANDFILL IN HELSINKI, SOUTHERN FINLAND}

Ämmässuo is a large municipal landfill of Helsinki region (one million people). The landfill area has been mapped in national airborne mapping program (1984) before the operation of the landfill started. At the end of 1993 GSF made airborne geophysical measurements as contract work for the city. The objective of airborne surveys was to map regionally the landfill area and to verify if environmental impacts in the vicinity of the landfill can be detected. The 1993 surveys were carried out in the same north-south flight direction as in 1984 but using tighter (100 meter) line spacing.

Comparison of the 1984 and 1993 results indicates several changes in the environment. Total field magnetic data from 1984 show weak magnetic gradients but no local magnetic anomalies because the granitic bedrock is non-magnetic. In the new (1993) results the landfill causes strong magnetic anomalies (magnitude about 1000 $\mathrm{nT}$ ). The anomalies indicate metallic waste and metal constructions. By comparing the total radiation maps, it was possible to estimate changes of moisture and soil thickness.

From the electromagnetic quadrature maps one can see that the strongest anomalies on the 1993 map are caused by the landfill waste and human structures. On the 1984 map there are moderate anomalies associated with the small bog inside the current landfill and with the larger bog north of the landfill. The change of the anomaly related to the northern bog has been estimated quantitatively by layer model interpretation. According to the 
1984 results the source of the anomaly is a 5 meter thick 200 ohmm layer. Based on the 1993 results the resistivity of the source has been decreased to $50 \mathrm{ohmm}$. At this site lies the sewage treatment sludge.

There are also some weak quadrature anomalies in 1993 results which are not seen in the 1984 results. The reason for these anomalies is uncertain, but small differences between the 1984 and 1993 results can be caused by different line spacings and slight variations in the flight altitude.

There is no evidence of significant leakages from the Ämmässuo landfill.

\section{CONCLUSIONS}

Geological Survey of Finland has carried out low-altitude airborne geophysical surveys since 1972. The multisensor measurement system includes two high-precision cesium magnetometers, an electromagnetic unit and a gamma-ray spectrometer. The airborne data provides excellent material also for environmental applications. Systematic airborne geophysical results can be used to detect and map rapidly contaminant plumes from landfills at regional scale.

The electromagnetic quadrature component is particularly sensitive even to small changes in conductivity, but also other aerogeophysical data can be utilised. Environmental impacts can be studied more precisely if repeated measurements are carried out. By comparing the old and new results, the changes in the environment can be distinguished more reliably from natural variations. Geophysical ground surveys and analyses of geochemical samples are required to map environmental effects in detail.

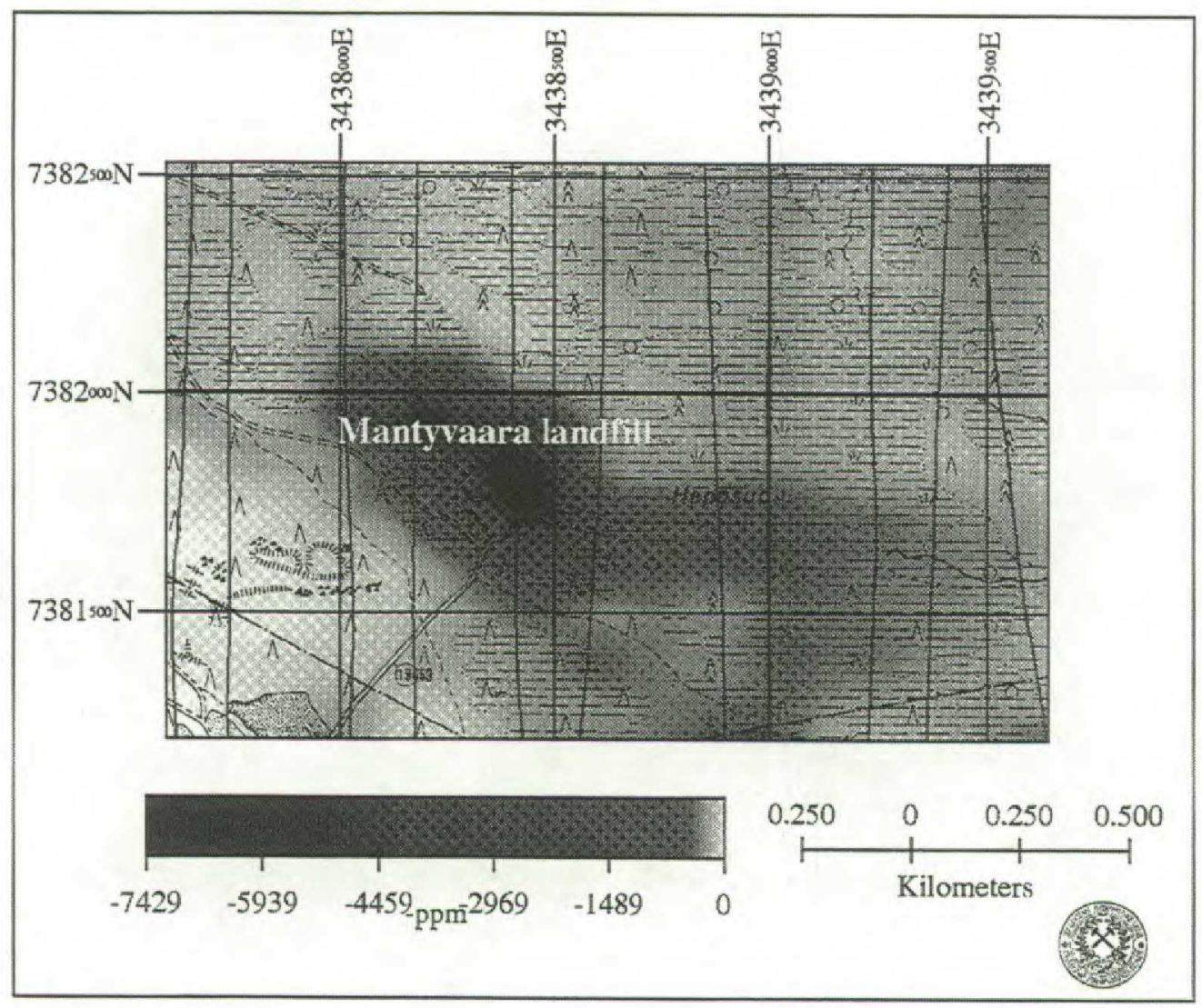

Fig. 1. AEM quadrature map of Mäntyvaara. Flight lines are marked. 


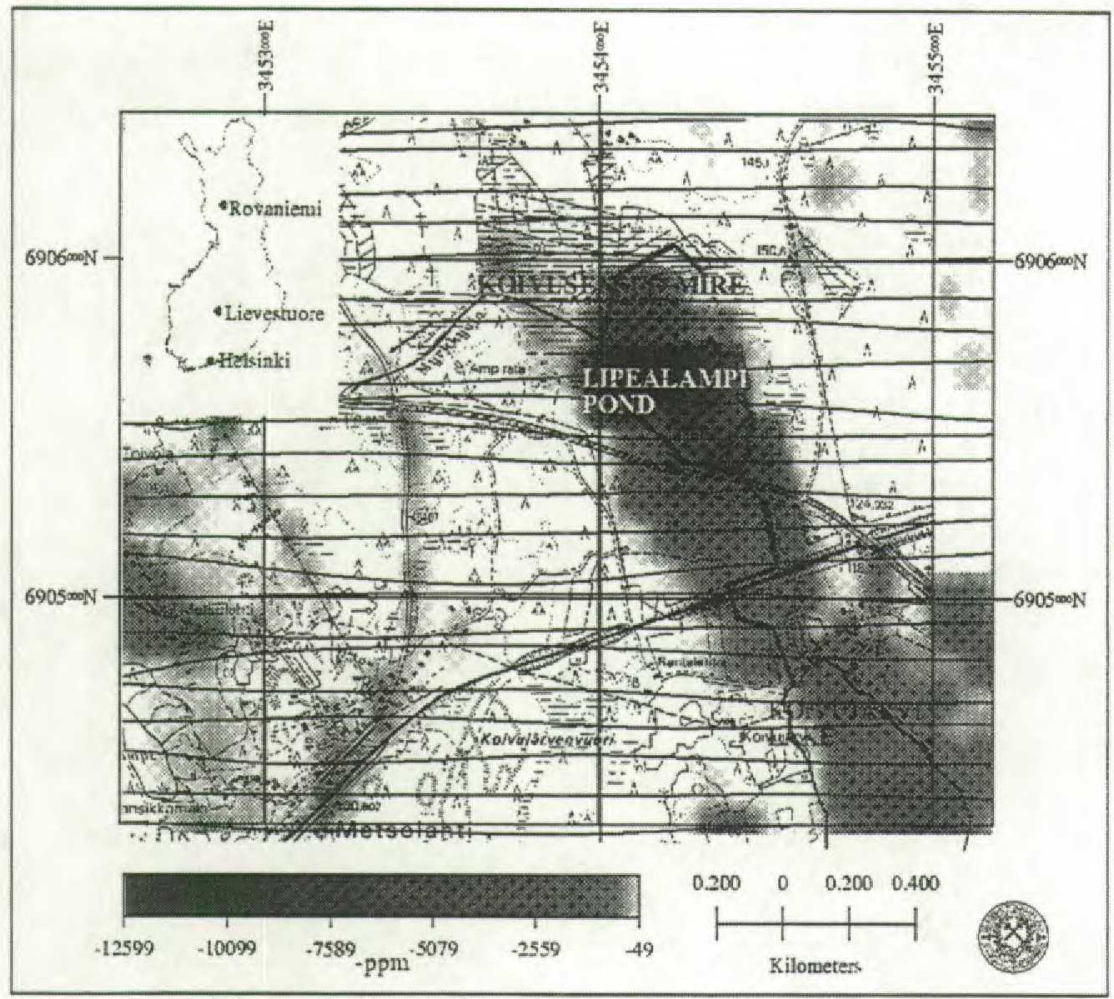

Fig. 2 Location map and AEM quadrature map of the Lievestuore area (measurement frequency $=14368 \mathrm{~Hz}$ ). Flight lines are marked.

\section{REFERENCES}

Hannula, P. and Lanne E. 1995. Environmental study of the refuse dump at Rovaniemi by geophysical and geochemical methods (summary in English). Geologian tutkimuskeskuksen tutkimusraportti 128 (in Finnish).

Kurimo, M., Oksama, M. and Valli, T., 1986. Airborne horizontal magnetic gradiometer system of the Geological Survey of Finland. EAEG, 48th meeting, Ostend, Belgium, 3-6 June 1986: Technical programme and abstracts of papers, p.81.

Mäkelä J., 1986. The effect of Lipeälampi pond at Lievestuore on groundwater. Turku University, Department of Quaternary Geology, study report: 59 p. (in Finnish).

Peltoniemi, M. 1982. Characteristics and results of an airborne electromagnetic method of geophysical surveying. Geol. Surv. Finland, Bull.321, 229 p.

Poikonen, A., 1991. The aerogeophysical measurement system of the Geological Survey of Finland. VTT symposium 127: 29-35 (in Finnish).

Puranen, R., Sulkanen, K. , Mäkelä, M., \& Grundström, A., 1997. A new apparatus for electric conductivity and temperature logging of soft sediments. In: Autio, S. (ed.) Geological Survey of Finland, Current Research 1995 - 1996. Geological Survey of Finland, Special Paper 23, 149 - 155 (in Press).

Vironmäki, J., Multala, J. and Peltoniemi, M., 1982. The multisensor aerogeophysical equipment of the Geological Survey of Finland. EAEG, 44th meeting, Cannes, June 8-11, 1982: Technical Programme and abstracts of papers, p. 60-61. 